\title{
Luminescence study of structural changes induced by laser cutting in diamond films
}

\author{
A. Cremades and J. Piqueras \\ Departamento de Física de Materiales, Facultad de Físicas, Universidad Complutense, 28040 Madrid, \\ Spain
}

(Received 30 January 1995; accepted for publication 10 May 1995)

\begin{abstract}
The effect of laser cutting on the structure of a chemical vapor deposited diamond film has been investigated by cathodoluminescence $(\mathrm{CL})$ in the scanning electron microscope. The variation of particle morphology and CL spectra as a function of the distance to the cutting edge is described and possible laser induced structural changes are discussed. At the damaged region total CL emission increases and nitrogen-vacancy centers are detected. (C) 1995 American Institute of Physics.
\end{abstract}

\section{INTRODUCTION}

The possibility of applications of diamond films grown from the chemical vapor deposited phase (CVD) ${ }^{1}$ is increasingly investigated. For many important applications the rough microstructure of the film surface is a drawback that needs to be minimized. This is the case of some microelectronics applications in which layered heterostructures including diamond films are needed or in optical coating applications. One of the methods to obtain a modification of the rough surface of the films is the laser irradiation. ${ }^{2-4}$ In addition, the laser dry etching process allows cutting or patterning of the diamond films. ${ }^{2,5}$ The use of excimer lasers for these treatments presents advantages, compared with other laser systems, of higher peak power and shorter wavelength, but on the other hand can induce marked changes in the properties of the irradiated area. In particular, laser irradiation induces the conversion of diamond to graphite as well as the generation of a conductive surface layer and possibly structural changes in the diamond grains close to the modified regions. Studies of laser induced changes using different characterization techniques as optical reflectometry, Raman spectroscopy, electrical conductivity, or atomic force microscopy, have been reported in the literature. ${ }^{3,5,6}$ In the present work cathodoluminescence (CL) in the scanning electron microscope (SEM) is used to investigate the effect of cutting a CVD diamond film with an excimer laser.

\section{EXPERIMENTAL METHOD}

A CVD film from Diamonex with a thickness of about $130 \mu \mathrm{m}$ was used. For the laser cutting a $308 \mathrm{~nm}$ Siemens XP 2020 excimer laser with a repetition rate of $10 \mathrm{~Hz}$ was used. A mask was interposed before the lens. The total laser energy was $2 \mathrm{~J} /$ pulse. Approximately $1 \mathrm{~J}$ was measured behind the mask. The beam was focused to a spot size of about $0.5 \times 0.5 \mathrm{~mm}$, resulting in an energy density of about 400 $\mathrm{J} / \mathrm{cm}^{2}$ at the sample. The laser cutting was performed in air.

The samples were observed in the emissive and CL modes in a Hitachi S-2500 scanning electron microscope at an accelerating voltage of $30 \mathrm{keV}$ and temperatures between 80 and $300 \mathrm{~K}$. The experimental arrangement has been previously described. ${ }^{7}$

\section{RESULTS}

Secondary electron images show the existence of regions with different morphology near the edge cut with the excimer laser. Close to the edge a smooth region appears, hereinafter called $A$, in which the laser has produced a high amount of material removal, as observed in Fig. 1. The surface of this region shows either a very smooth appearance or the structure shown in Fig. 2. At this structure, rests of the original grains with material recrystallization at its surface are recognized.

At increasing distance from the edge a fine stripe of diamond crystals followed by a region in which the presence of spheres is the predominant feature is observed (Fig. 3). The spheres seem to be a rounded modification of the original crystals (Fig. 4), and limit the background distribution of diamond crystals in the region apparently undamaged during cutting (Fig. 5).

CL spectra could be recorded in all the mentioned regions as well as the general distribution of relative CL intensity as a function of the distance to the edge. However, $\mathrm{CL}$ images do not appear to provide significative information of

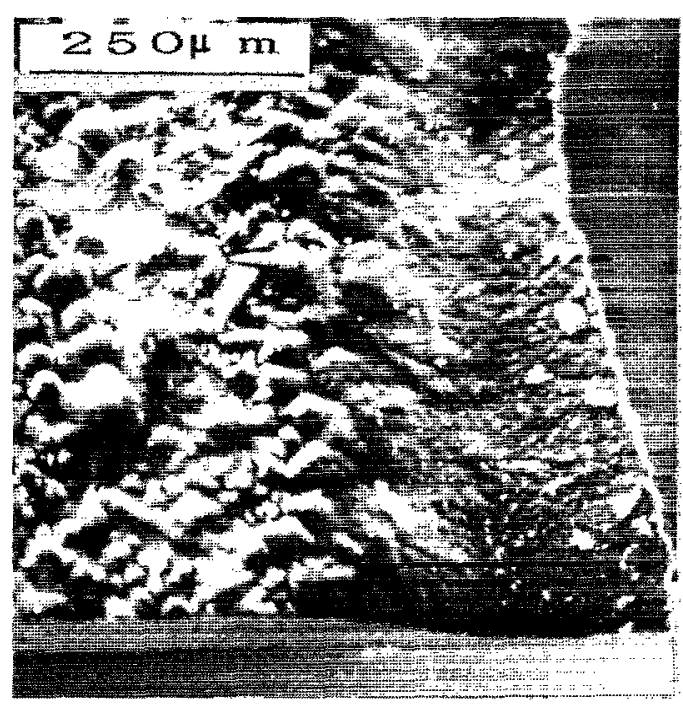

FIG. 1. Secondary electron image of the cut edge. A high amount of material removal can be observed. 


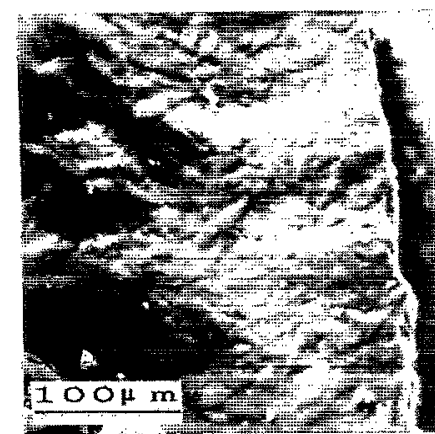

(a)

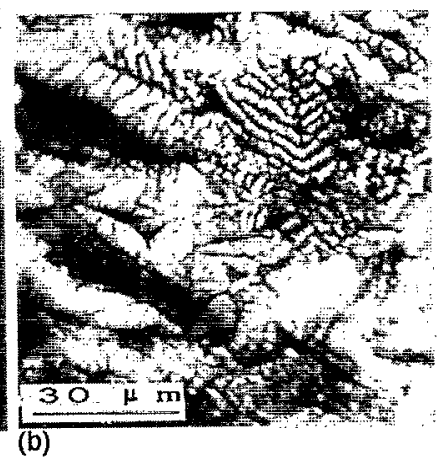

FIG. 2. Secondary electron image of the edge: (a) smooth region and (b) region with structure.

CL distribution at the local (grain size) level, due to the strong topographic effect in faceted crystals and spheres. CL images from the smooth area besides the edge show a certain correspondence with laser induced surface structure (Fig. 6). Figure 7 shows a CL intensity profile along a line perpendicular to the sample edge. There is a maximum of intensity near the edge and an intensity lower than the background in a wide region, part of the $A$ region, crystal and spheres as shown in Fig. 7. Features at a longer distance from the edge correspond to intensity fluctuations of the particular line scan along the crystalline area.

CL spectra of the $A$ region show the existence of two bands centered, respectively, at about 515 and $575 \mathrm{~nm}$, as Fig. 8 shows. Relative intensity of both bands depends on the area investigated and on the observation conditions in the electron microscope. The relative intensity of the $575 \mathrm{~nm}$ appears to be higher in the regions showing the granular-like structure of Fig. 2, as well as the total CL intensity.

Spectra are recorded under different focusing conditions of the electron beam on the samples to account for the radiative centers with a low concentration. ${ }^{7,8}$ Usually by defocusing, the intensity of deep level bands increases. In our case the $515 \mathrm{~nm}$ band is magnified in defocused spectra.

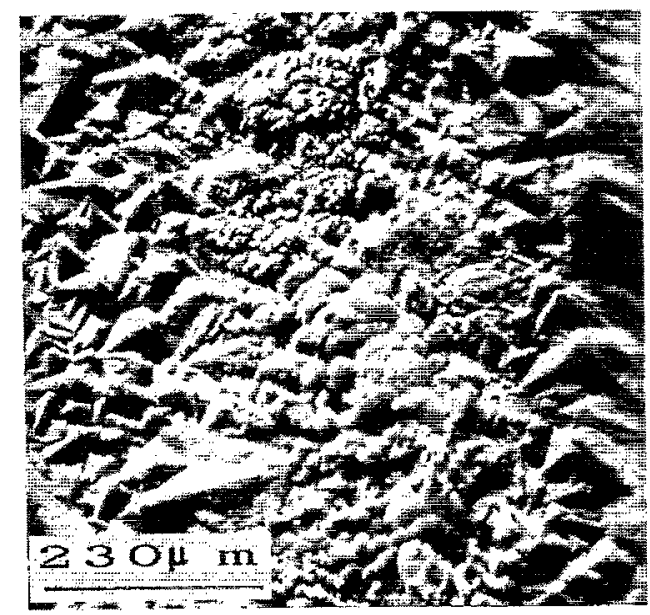

FIG. 3. Secondary electron image of the laser-modified region. On the left, original crystals; center, spheres; and on the right, rest of crystals and beginning of the smooth region at the edge.

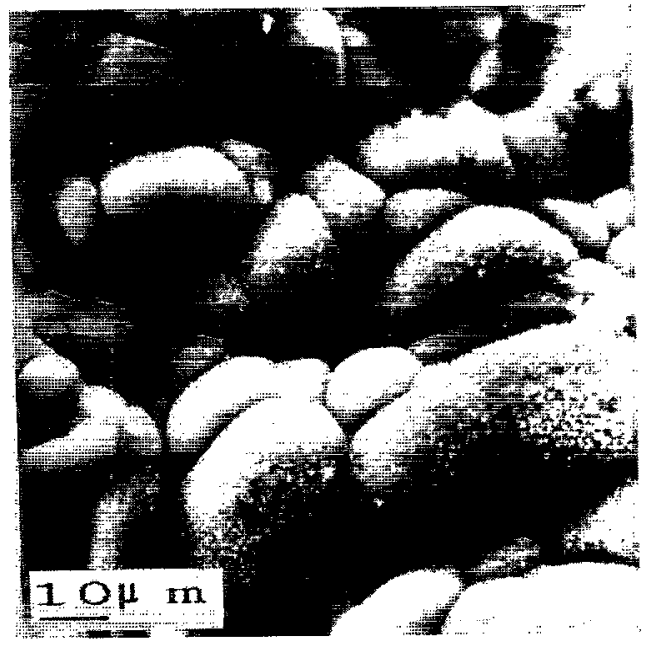

FIG. 4. Secondary electron image showing a detail of the spheres.

The other regions with different morphology at a distance from the edge, spheres, and crystals, together with the undamaged zone, show the spectra of Fig. 9, with a broadband centered in the blue spectra range. The undamaged crystalline region shows the highest emission while the emission is reduced in the spheres and the nearby located crystals. Although the spectra of Fig. 9 show a predominant blue emission, a band centered about $520 \mathrm{~nm}$ is also present and appears by defocusing the electron beam, as shown in Fig. 10 for the case of the spheres.

MicroRaman spectra from the $A$ region reveal the presence of graphite and amorphous material. Due to the metallization in the rest of the sample no microRaman measurements were carried out.

\section{DISCUSSION}

The presence of graphite in the $A$ region agrees with the often described ${ }^{2-5,9}$ formation of graphite during laser irradiation. The formation can be followed by sublimation of the

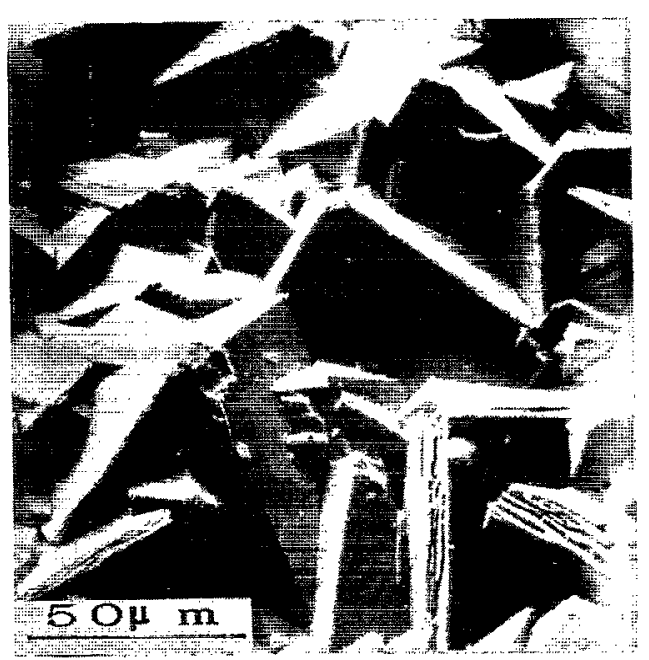

FIG. 5. Secondary electron image of the undamaged zone of the sample. 


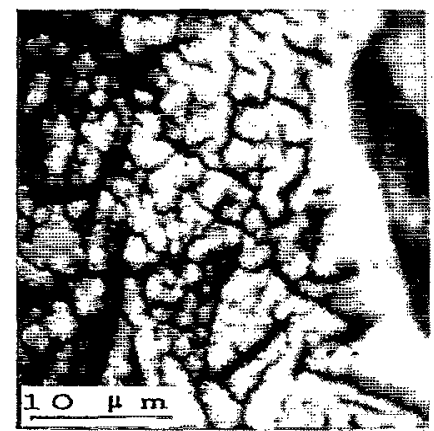

(a)

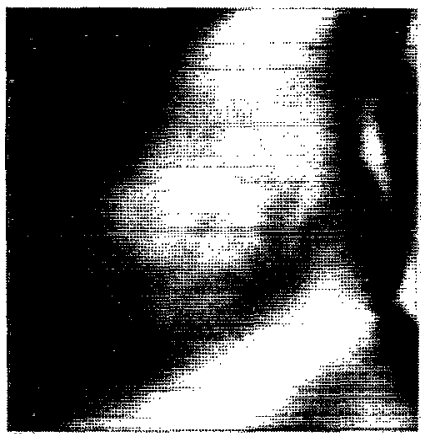

(b)

FIG. 6 . (a) Secondary electron image of the edge and (b) CL image of the same region.

graphite layer while a thin conductive layer remains. Typical thickness of the modified surface region has been reported to be about $150-200 \mathrm{~nm}$. Since the CL signal in the SEM arises from a region extending up to about $2 \mu \mathrm{m}$ from the sample surface, the CL spectra provide information about the diamond phase below the graphite layer. The surface layer absorbs part of the radiation emitted from the interior. Figure 7 shows a reduced intensity in the region near the sample edge with the exception of a strong luminescent narrow fringe at the border in which highest temperatures were achieved during the layer treatment. As possible reasons for the high luminescence in this fringe, a reduced optical absorption at the surface, due to sublimation of at least part of the graphite layer, and structural changes of the underlaying diamond during heating can be considered. Since we have not measured the thickness of the graphite layer along the $A$ regions, the first possibility has not been checked and is merely suggested here. This suggestion is supported by the $\mathrm{CL}$ image of Fig. 6 in which the luminescence clearly arises from the underlaying region. On the other hand, structural changes are revealed in the CL spectra of the $A$ region. In Fig. 8 it is observed that in this region two luminescence bands appear at about 515 and $575 \mathrm{~nm}$, respectively, instead of the blue

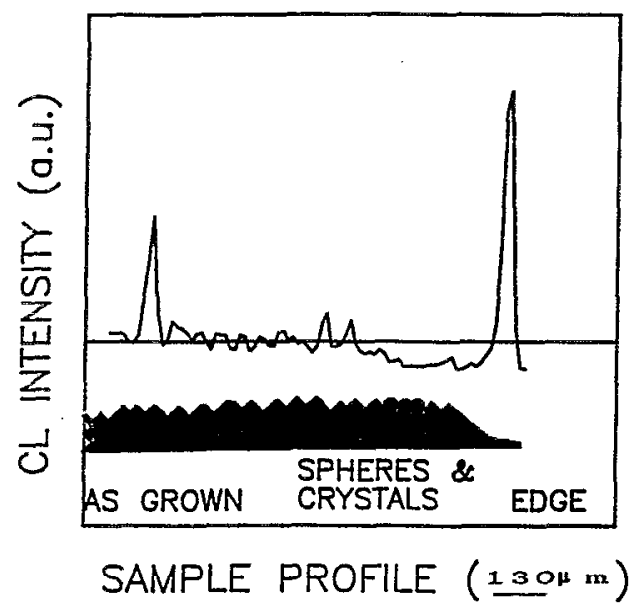

FIG. 7. CL intensity profile as a function of the distance to the border. The straight line is the luminescence background level. The thickness of the sample is not scaled.

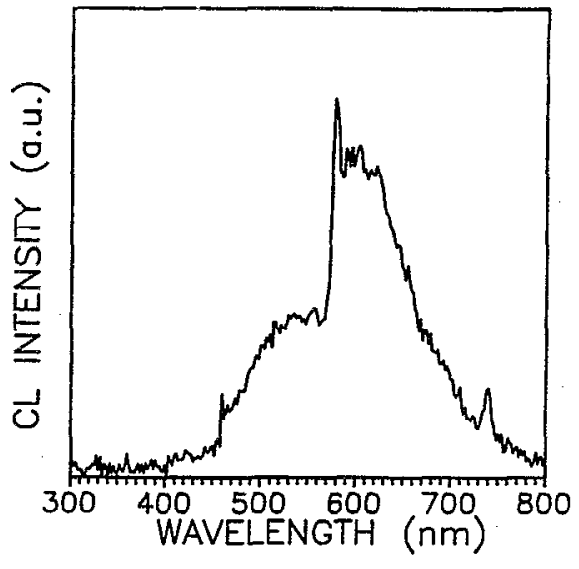

FIG. 8. CL spectrum of the cut edge.

band that dominates the spectra in the rest of the sample (Fig. 9). The green emission appearing in the $A$ region corresponds to the emission between 515 and $575 \mathrm{~nm}$ often described in diamond (Refs. 10-12), which has been attributed to centers containing nitrogen atoms and vacancies. The origin of this band would be the elevated temperature reached in this region during laser treatment and the subsequent defect diffusion. Davies and Collins ${ }^{13}$ have reported that on annealing, diamond vacancies are trapped at nitrogen. This would explain the present observations. The fact that no blue emission is observed in this region can be partly due to the high increase of the green emission but also to an annealing induced reduction of the blue band intensity. The latter would happen if dislocations involved in luminescence at the blue range $e^{14,15}$ are annealed out during laser irradiation.

The $736 \mathrm{~nm}$ peak observed in Fig. 8 is thought to be Si-related, an effect from the substrate, and not the GR1 band, as this is reported to anneal out at low temperatures $\left(800^{\circ} \mathrm{C}\right)$ (Ref. 11) compared to the temperature reached during the laser cutting. The high amount of material removal in this region supports the possibility of detecting a center related to $\mathrm{Si}$ atoms from the substrate diffused into the diamond matrix. Figure 9 indicates that in the other regions of the sample, spheres and crystals, the CL of the as-grown

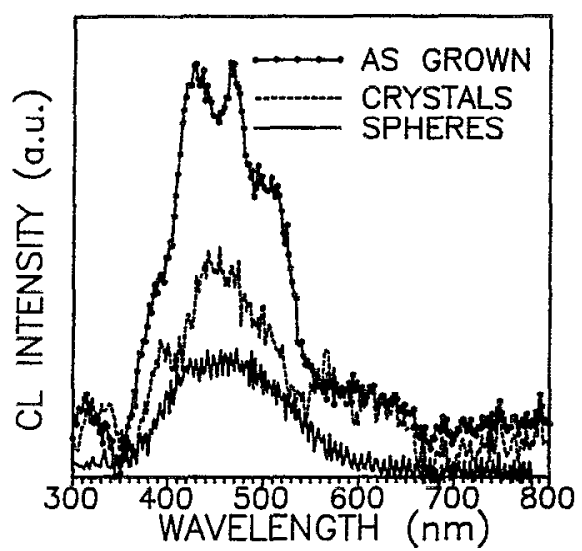

FIG. 9. Composition of the CL spectra of the spheres and nearby crystals as well as the undamaged zone of the sample. 


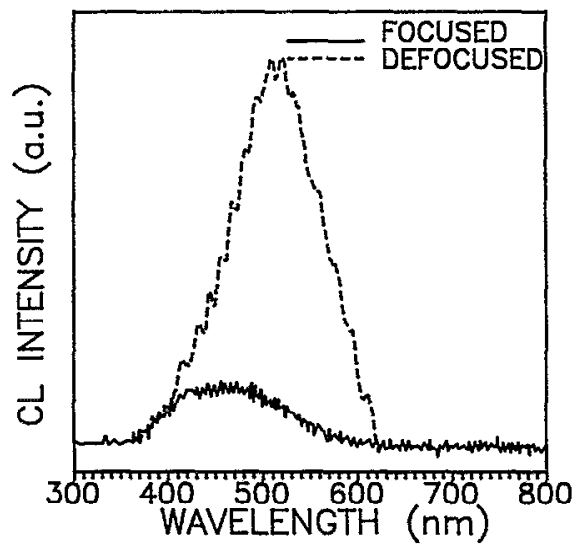

FIG. 10. CL spectra of the spheres with fucused and defocused beam.

material is qualitatively conserved, with peaks in the blue and green ranges, although with reduced intensity up to a distance from the edge, probably because of the appearance of a graphite layer. Structural changes as formation of vacancy-nitrogen complexes are restricted to a fringe besides the cut edge.

\section{CONCLUSIONS}

CL microscopy complements the information that scanning electron microscopy in the secondary electron mode provides on the effect of laser cutting in CVD diamond films. CL spectra show that in a region with a high amount of material removal at the cutting edge the treatment induces the formation of vacancy-nitrogen complexes. In nearby located regions the CL spectral features of the as-grown material are qualitatively conserved but with reduced intensity.

\section{ACKNOWLEDGMENTS}

This work has been supported by DGICT (Project Nos. PB93-1256 and HP93-004). We thank Professor J. Jimenez and P. Martin for the microRaman measurement. We thank Dr. Wolfgang (Siemens) for suggestions on this work and Dr. Roas (Siemens) for making the laser treatment.

${ }^{1}$ B. V. Spitsyn, L. L. Builov, and B. V. Derjaguin, J. Cryst. Growth 52, 219 (1981).

${ }^{2}$ V. P. Ageev, L. L. Builov, V. I. Konov, A. V. Kuzmichev, S. M. Pimenov, A. M. Prokhorov, V. G. Ralchenko, B. V. Spitsyn, and N. I. Chapliev, Sov. Phys. Dokl. 33, 840 (1988).

${ }^{3}$ U. Bögli, A. Blatter, S. M. Pimenov, A. A. Smolin, and V. I. Konov, Diamond Relat. Mater. 2, 782 (1993).

${ }^{4}$ A. Boudina, E. Fitzer, G. Wahl, and H. Esrom, Diamond Relat. Mater. 2, 678 (1993)

${ }^{5}$ C. Johnston, P. R. Chalker, I. M. Buckley-Golder, P. J. Marsden, and S. W. Williams, Diamond Relat. Mater. 2, 829 (1993).

${ }^{6}$ U. Bögli, A. Blatter, A. Bächli, R. Lüthi, and E. Meyer, Diamond Relat. Mater. 2, 924 (1993).

${ }^{7}$ A. Cremades, F. Domínguez-Adame, and J. Piqueras, J. Appl. Phys. 74, 5726 (1993).

${ }^{8}$ H. C. Casey and J. S. Jayson, J. Appl. Phys. 42, 2774 (1971).

${ }^{9}$ S. M. Pimenov, A. A. Smolin, V. G. Ralchenko, V. I. Konov, S. V. Likhanski, I. A. Veselovski, G. A. Sokolina, S. V. Bantsekov, and B. V. Spitsyn, Diamond Relat. Mater. 2, 291 (1993).

${ }^{10} \mathrm{~J}$. A. Freitas, Jr., K. Doverspikle, and P. B. Klein, Diamond Relat. Mater. 3. 821 (1994).

${ }^{11}$ J. Ruan and W. J. Choyke, J. Appl. Phys. 69, 6632 (1991).

${ }^{12}$ N. Fujimori and Y. Nishibayashi, Diamond Relat. Mater. 2, 762 (1993).

${ }^{13}$ G. Davies and A. T. Collins, Diamond Relat. Mater. 2, 80 (1993).

${ }^{14}$ R. J. Graham, T. D. Moustakas, and M. M. Disko, J. Appl. Phys. 69, 3212 (1991).

${ }^{15}$ R. J. Graham and K. V. Ravi, Appl. Phys. Lett. 60, 1310 (1992). 
Journal of Applied Physics is copyrighted by the American Institute of Physics (AIP). Redistribution of journal material is subject to the AIP online journal license and/or AIP copyright. For more information, see http://ojps.aip.org/japo/japcr/jsp

Copyright of Journal of Applied Physics is the property of American Institute of Physics and its content may not be copied or emailed to multiple sites or posted to a listserv without the copyright holder's express written permission. However, users may print, download, or email articles for individual use. 
Journal of Applied Physics is copyrighted by the American Institute of Physics (AIP). Redistribution of journal material is subject to the AIP online journal license and/or AIP copyright. For more information, see http://ojps.aip.org/japo/japcr/jsp 